\title{
Modeling of Heavy Armocement Deformation for the Conical Shape of the Heat Accumulator Body by the Methods of Computer Engineering
}

\author{
Alexander Chugunov ${ }^{1}$, Dmitry Shishov ${ }^{1}$ and Aleksandr Nikonorov $^{2 *}$ and Vladimir Filatov ${ }^{3}$ \\ ${ }^{1}$ St.Petersburg State Agrarian University, Peterburgskoye shosse, 2, St. Petersburg-Pushkin, 196601, \\ Russia \\ ${ }^{2}$ Peter the Great St.Petersburg Polytechnic University, Polytechnicheskaya, 29, St. Petersburg, \\ 195251, Russia \\ ${ }^{3}$ Moscow State University of Civil Engineering, Yaroslavskoye Shosse, 26, Moscow, 129337, Russia
}

\begin{abstract}
The computer simulation of the structural material is required to study the stress-strain state of the structural material of the high-pressure hull (in particular, the heat accumulator body). Laboratory experiment requires significant financial expenses, which is a significant drawback of this type of study. Therefore, the authors considered finite element modeling of structural material by adapting modern software systems for calculating the considered models. A modern design solution for highpressure hulls of heat accumulators made of non-prestressed reinforced concrete involves the usage of heavy reinforcement cement as a structural material. The proposed method allows gaining rather certain calculations avoiding time-consuming laboratory research.
\end{abstract}

\section{Introduction}

The end parts of high-pressure hulls (HPH) from complex shape heavy reinforcement cement (HRC) have conical constrictions for the interface between the wall and the bottom (end parts) of the body according to the principle of "plug" [1]. With this kind of surface (conical), the direction of action of the forces and the direction of the arrangement of the reinforcing bars in the HRC do not coincide, i.e.oblique the reinforcement of HPH could be observed. The angle of inclination of reinforcing bars is the angle between the generatrix of the surface of the conical part of the HPH and the vertical [2-5].

Since the angle of inclination of the reinforcing bars affects the HRC of the bottoms "plugs" [1], it is necessary to consider the work of conical surfaces with different angle of inclination of the generating surface in order to estimate the stress-strain state (SSS) of the bottom of heavy concrete and the conical part of the HPH from the HRC itself, consequently defining the rational shape of this part [6-8]. Within the framework of this work, it was sufficient to study the work of the HC of the conical part of the HPH with the slopes of the reinforcing bars $45^{\circ}, 35^{0}, 25^{0}$.

\footnotetext{
* Corresponding author: coolhabit@yandex.ru
} 
Simulation of heavy reinforcement cement without cracks and with oblique reinforcement with biaxial SSS by computer-engineering methods was considered in [9-11].

The initial data of the «beam-wall» model are taken as follows (Fig.1):

- $\quad$ reinforcement - Ø5 B500 (Bp-I) $(\mathrm{ES}=2,0 \cdot 108 \mathrm{kPa}) \mathrm{c} \mathrm{FS}=0,0000196 \mathrm{~m}^{2}$;

- $\quad$ pitch of reinforcing bars $-13 \mathrm{~mm}$;

- $\quad$ concretes class B30 $(\mathrm{Eb}=32,5 \cdot 106 \mathrm{kPa})$;

- dimensions of finite elements - plates $1 \times 1 \mathrm{~mm}$;

- $\quad$ overall dimensions of the layer $588,320 \times 588,320 \mathrm{~mm}$;

- $\quad$ angle of inclination of reinforcing bars 450,350, 250;

- thickness of concrete plate $-10 \mathrm{~mm}$;

- stiffness parameters of steel reinforcing bars: $E F=3337,942 \mathrm{kN}$; $\mathrm{y} 1=\mathrm{y} 2=\mathrm{z} 1=\mathrm{z} 2=0,625 \mathrm{~mm}$ (circular cross-section); $\mathrm{EJ}=5215,535 \mathrm{kN} \cdot \mathrm{mm}^{2}$.

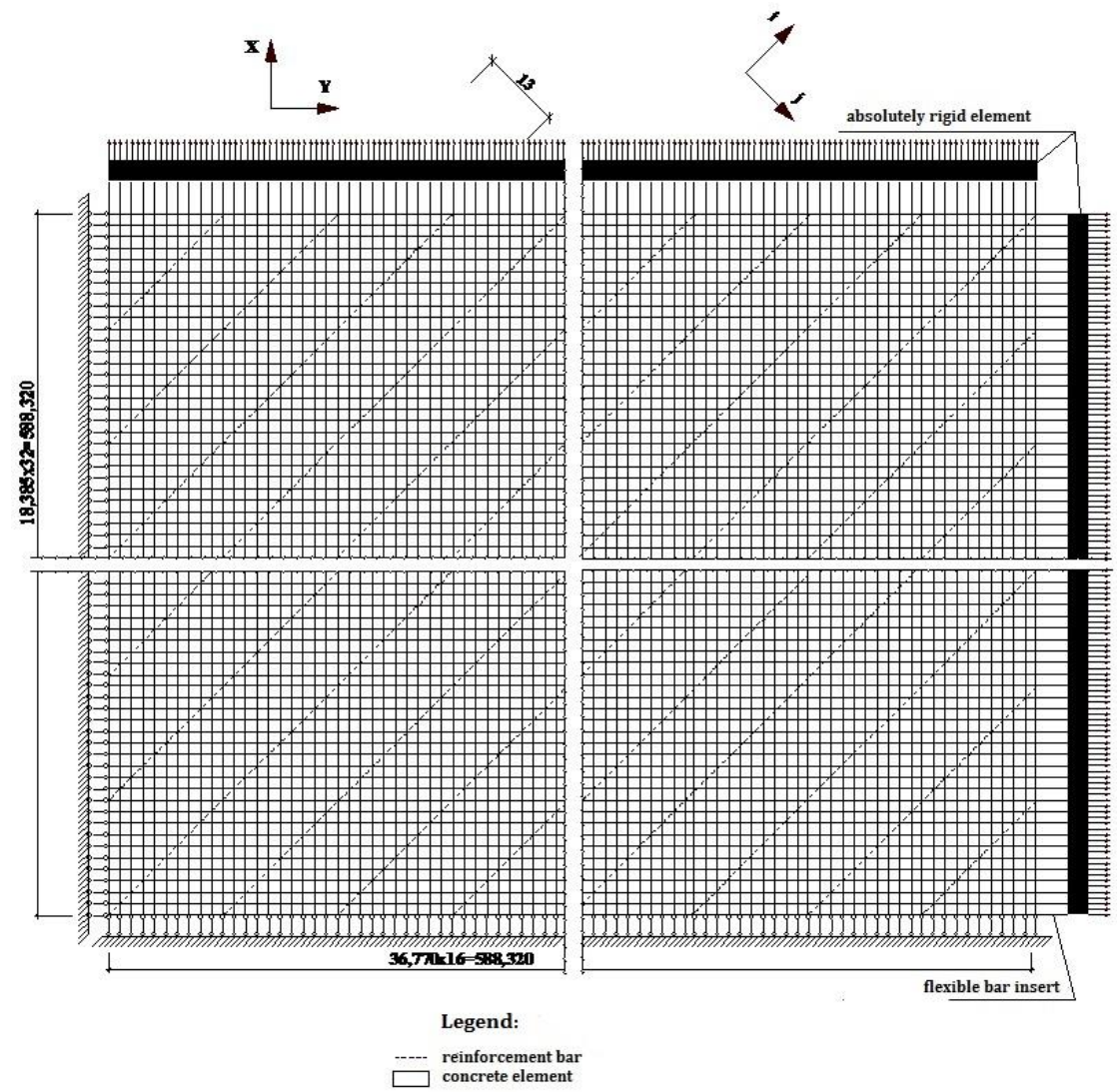

Fig. 1. General view of the finite-element model of the layer from the HRC, located in a biaxial stressed state: oblique reinforcement, the angle of inclination of reinforcing bars $45^{\circ}$.

\section{Materials and methods}

A lamellar type of layer models («beam-wall») was used to simulate the deformation of the HRC with oblique reinforcement at an angle of 450. At an angle of inclination of the reinforcing bar, which differs from 450 , the elementary plate (final element) of the concrete matrix must have a rectangular shape, or it is possible to use a rod model (with unit cell dimensions of $1 \times 1 \mathrm{~mm}$ ). In order to interface the reinforcement with concrete elements 
(rods) nodes within the cell must be inserted [12]. The characteristic features of the construction of rod models will be as follows [13-16]. The external load is applied to the two mutually orthogonal sides of the model through absolutely rigid plate elements, which are connected to the model by means of flexible rods to avoid an uneven load distribution between the model elements. The hypothesis of flat sections and the appearance of transverse shear strains were fulfilled [17-19]. Rigid elements are given flexural rigidity 10 times greater than the rigidity of steel rods: $E=2 \cdot 106 \mathrm{MPa} ; v=3$. Flexible rods that allow transverse deformations of the model have a length of $5 \mathrm{~mm}$ and have a circular crosssection of $1 \mathrm{~mm} 2$, as well as a large longitudinal stiffness $\mathrm{EF}=2000 \mathrm{kN}(\mathrm{E}=2 * 106 \mathrm{MPa})$, and bending stiffness is EJy=0,00016 kN/m2.

A numerical experiment (calculation) of «beam-wall» models made it possible to determine the relative elongations of the model in the $\mathrm{X}$ and $\mathrm{Y}$ directions and the normal stresses in the cross sections of the layer (Table 1). The integral modulus of elasticity in any direction, indicated in Table 1, was determined according to Hooke's law by Equation 1.

$$
E=\sigma / \varepsilon
$$

Comparing the obtained values of the integral elastic characteristics in the direction $\mathrm{X}$ for the HRC in biaxial SSS (Table 1) with the values for the HRC being in the uniaxial SSS [3] with equal percentages and the reinforcement properties of the layer, we should note the following:

1. The values of elasticity moduli under uniaxial SSS [3] and biaxial SSS in the X direction differ by $5 \ldots 8 \%$, with $\mathrm{EZ}>\mathrm{EX}$;

2. Values of elastic characteristics according to Table. 1 in orthogonal directions with oblique reinforcement differ approximately by $3.5 \ldots 4 \%$, with EX> EY;

3. At an angle of inclination of the reinforcing bars at 450 , the values of the elastic characteristics in the principal directions are approximately equal, which is natural;

4. The relative deformations of the model in biaxial SSS are greater (by approximately $4 \ldots 6 \%$ ) than in the case of uniaxial SSS.

With an increase in the external load, there comes a time when the limit values of either deformation or strength characteristics of the material appear in a number of concrete elements (rods). This is the moment of the onset of the elastoplastic stage of work (the work of the material with microcracks). Computer modeling of deformation of heavy armocement for the conical part of the heat accumulator body is considered in [4].

Table 1. Obtained values of elastic charactetristics.

\begin{tabular}{|c|c|c|c|c|c|c|}
\hline $\begin{array}{c}\text { Inlcine angle of } \\
\text { reinforcing bars }\end{array}$ & $\sigma_{\mathrm{X}}, \mathrm{Mpa}$ & $\varepsilon_{\mathrm{X}}$, rel.unit & $\begin{array}{c}\mathrm{EX}, \\
\mathrm{MPa} \times \\
10^{-4}\end{array}$ & $\sigma_{\mathrm{Y}, \mathrm{MPa}}$ & $\varepsilon \mathrm{\varepsilon}$, rel.unit & $\begin{array}{c}\mathrm{EY}, \\
\mathrm{MPa} \times 10^{-4}\end{array}$ \\
\hline $45^{0}$ & 13,129 & 0,000285 & 4,604 & 26,258 & 0,000571 & 4,600 \\
\hline $35^{0}$ & 13,129 & 0,000291 & 4,512 & 26,258 & 0,000603 & 4,354 \\
\hline $25^{0}$ & 13,129 & 0,000297 & 4,417 & 26,258 & 0,000619 & 4,240 \\
\hline
\end{tabular}

\section{Results and discussions}

The process of crack formation begins with the initiation of microcracks. The studied microcracks, as well as in case of coaxial reinforcement with biaxial VAT, should be 
located in the central part of the model, therefore only deformation pictures of the central part of the model are considered (Fig. 2).

As a factor of crack formation and growth of cracks, the force factor was considered. It realized when a number of concrete elements (rods) shows the limiting values of the strength characteristics of concrete.

The method of formation and growth of microcracks is used the same as the technique described in [5]. The following procedure for the formation of a microcrack is characteristic for rod HRC models and in the subsequent - a trunk crack. When a stress is greater in one of the concrete rods of the model than the resistance of the concrete to the stretching Rbt,ser (force factor) or when one of the concrete rods of the model has a relative deformation greater than the limiting ebtu (deformation factor), then this rod must be shortened by introduction of an additional node (Fig. 3).

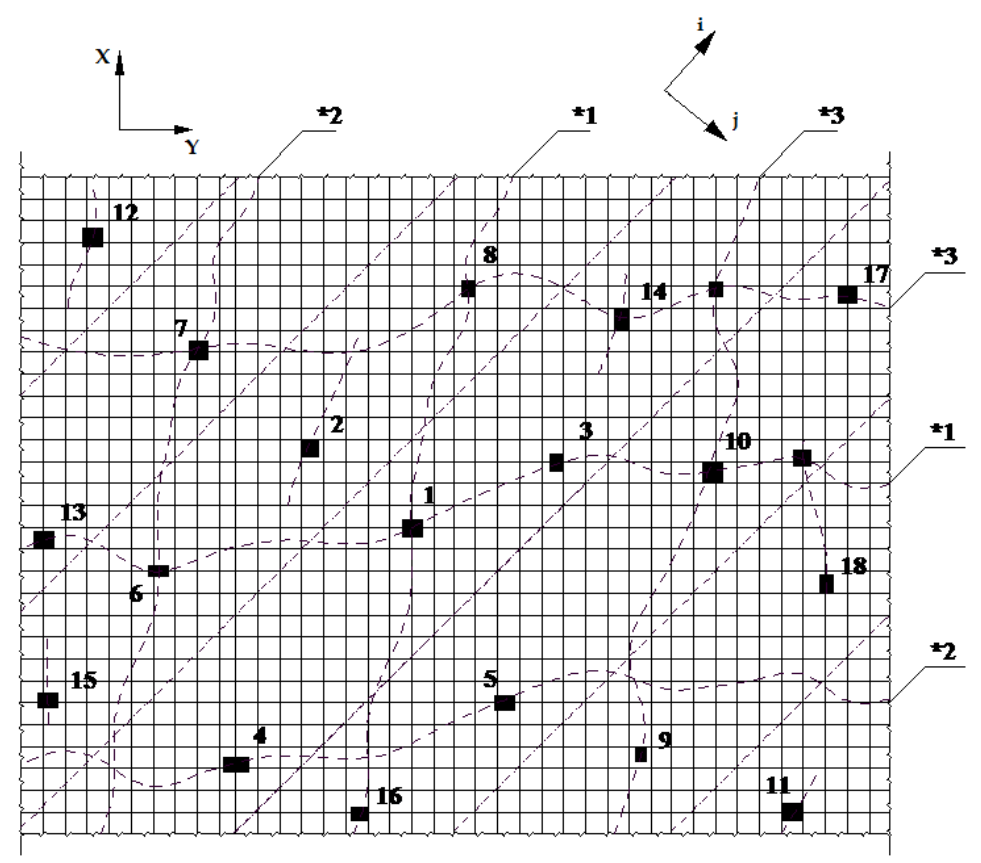

Note:

on the fragment of the model scheme, the sequence of formation of microcracks is numbered and trunk microcracks are numbered (marked with "*")

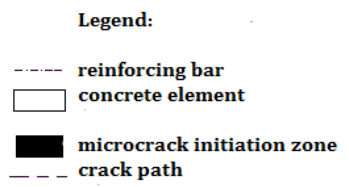

Fig. 2. The sequence of microcrack formation in the HRC layer model (oblique reinforcement, tilting angle of reinforcing bars 450 ), located in a biaxial stress state. 


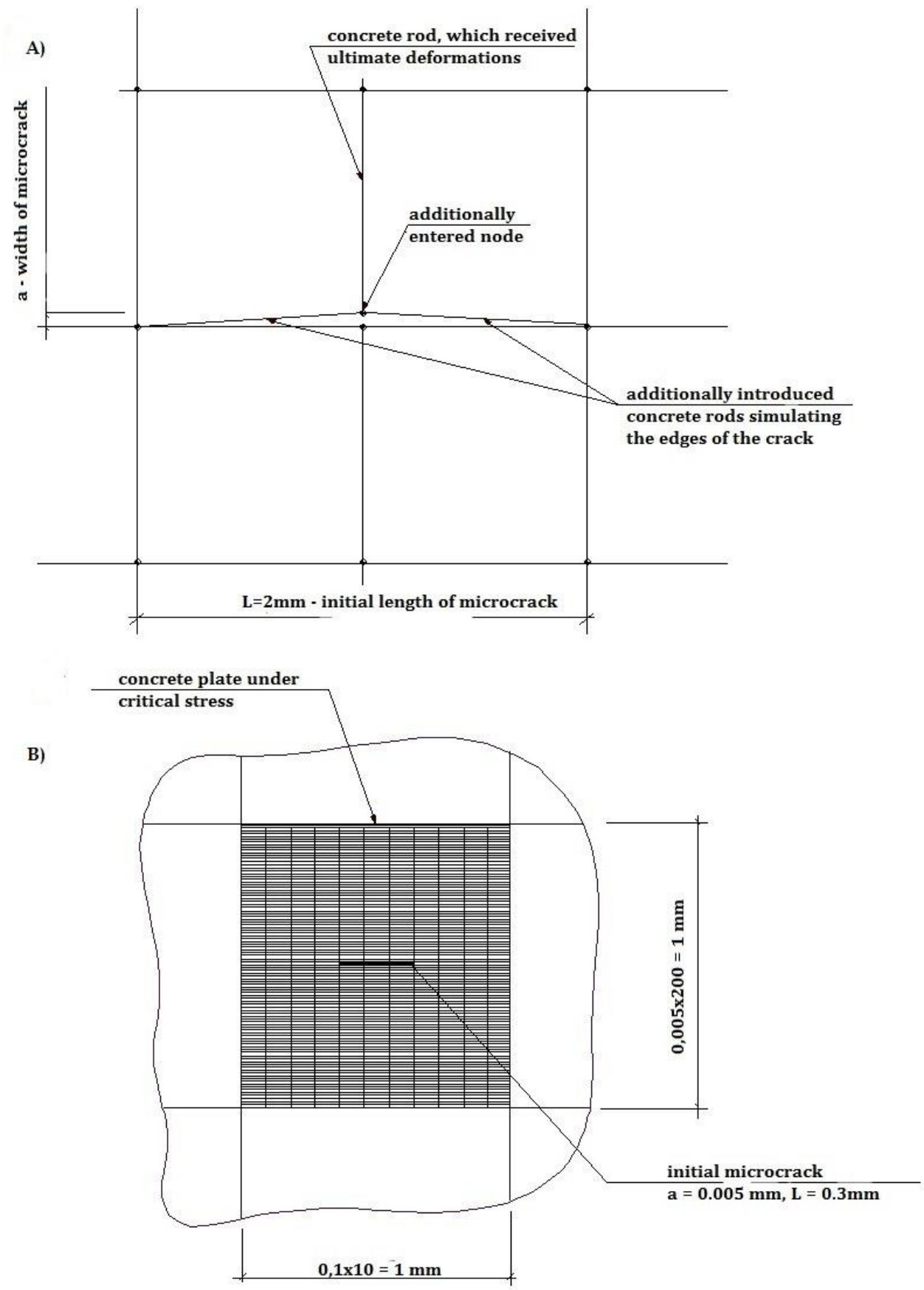

Fig. 3. Scheme of microcrack formation: a - in the rod model; b - in the «beam-wall» model.

The additional node is disposed in the direction of opening the crack $(Z)$ from the original location of the node by an amount equal to the minimum fixed microcrack by acetone (namely, by the value $\mathrm{a}=0.005 \mathrm{~mm}$ ). An innovative node is connected by means of two concrete rods with model nodes in order to form a microcrack. The width of the 
crack opening - movement of an additional node in the $\mathrm{Z}$ direction with respect to the model node. It is necessary to include additional nodes by the same procedure, placing them on either side of the crack section (the original node) with increasing crack length. In addition, in this case, with additional concrete rods, it is necessary to connect the frame assemblies to the extreme additional nodes of the model. It is required to crush the concrete plate (the one in which either extreme deformations or stresses of large concrete resistances to tension are observed) for the artificial formation of a microcrack in the model of a layer of «beam-wall» type: the number of crushes in the $\mathrm{Z}$ direction is 200 , and in the $\mathrm{X}-10$. This operation allows creating an initial microcrack with the following dimensions: $a=0.005$ $\mathrm{mm}, \mathrm{L}=0.3 \mathrm{~mm}$ (Fig. 3). The further growth of cracks is carried out as follows. An increase in the width of crack opening occurs by removing horizontal plates of the subsystem obtained by crushing the plate, and increasing the length of the crack by removing the vertical plates of the subsystem. If the dimensions of the crack go beyond the dimensions of the plate (with a length of cracks in excess of $1 \mathrm{~mm}$ ), then additional crushing of the adjacent concrete plates of the model is carried out in the direction of the development of the crack. When choosing the factor that influences the formation and growth of a crack, it should be noted that simultaneously with the appearance of extreme stresses, the concrete plate also receives extreme deformations, so here the microcrack formation factor can be selected. It is more convenient to take the force factor from technical motives. The curves for the dependence of the crack opening width on the external load (stresses) a- $\sigma$ could be built to analyze the operation of models, as well as on the stresses in the a- $\sigma \mathrm{s}$, on the crack length from the external load L- $\sigma$, on the change in the integral deformation characteristic of the HRC from the external load E- $\sigma$ and a plot of the relative deformations versus normal stresses $\varepsilon-\sigma$.

Some features of the results of numerical model experiments should be pointed out. The formation of the first microcracks occurred in the central part of the model (Fig. 2). Subsequent microcracks formed approximately diametrically opposite to the first microcracks. For example, the sequence of microcrack formation is shown on the characteristic fragment of the model scheme with the direction of the reinforcing bars at an angle of 450 (Fig. 2).

The initial length of each crack in the «beam-wall» model was artificially set at $0.3 \mathrm{~mm}$. then, because of the growth of the opening width of the microcrack «a», its length increased. The path of crack growth is shown in Fig. 2. The number of trunk cracks at the final stage of cracking is indicated in the Table 2.

Table 2. Results of numerical experiments.

\begin{tabular}{|c|c|c|c|c|c|c|}
\hline \multirow{2}{*}{ Model } & \multicolumn{3}{|c|}{$\mathrm{i}$ - direction } & \multicolumn{3}{c|}{$\mathrm{j}$ - direction } \\
\cline { 2 - 7 } & $45^{0}$ & $35^{0}$ & $25^{0}$ & $45^{0}$ & $35^{0}$ & $25^{0}$ \\
\hline Number of trunk cracks & 33 & 30 & 16 & 18 & 17 & 33 \\
\hline $\begin{array}{c}\text { Number of microcracks } \\
*\end{array}$ & $1400 \div$ \\
1600 & $1350 \div 1500$ & $\begin{array}{c}1050 \div \\
1200\end{array}$ & $\begin{array}{c}1100 \div \\
1300\end{array}$ & $\begin{array}{c}1100 \div \\
1250\end{array}$ & $\begin{array}{c}1250 \div \\
1450\end{array}$ \\
\hline
\end{tabular}

* - those microcracks that did not become trunk cracks.

The growth of microcracks, which did not become trunk, practically did not occur (the average value of the opening width of such cracks was $\approx 0.01 \mathrm{~mm}$, and lengths $-\approx 2.25 \mathrm{~mm}$ ).

The pitch of the main cracks at the final stage of the crack formation was observed to be stable (Table 3). 
Table 3. Pitch of the main cracks at the final stage of the crack formation.

\begin{tabular}{|l|c|c|c|c|c|c|}
\hline \multirow{2}{*}{ Model } & \multicolumn{3}{|c|}{ i - direction } & \multicolumn{3}{c|}{ j - direction } \\
\cline { 2 - 7 } & $45^{0}$ & $35^{0}$ & $25^{0}$ & $45^{0}$ & $35^{0}$ & $25^{0}$ \\
\hline Cracks pitch, mm & $10 \div 14$ & $11 \div 13$ & $9 \div 13$ & $20 \div 28$ & $22 \div 27$ & $23 \div 27$ \\
\hline
\end{tabular}

Estimating the results in Tables 2 and 3, we can conclude that there is a tendency, as in the case of coaxial reinforcement: the larger the pitch of the reinforcing bars, the greater the step (the smaller the number) of cracks oriented perpendicular to the considered direction.

At the stage of operation of the material with trunk cracks, a simultaneous occurrence of a main crack is observed in two directions $i$ and j simultaneously (Fig. 2).

The formation of the trunk crack occurs due to normal separation, and its appearance at the initial stage of growth was in hairline character. It should be pointed out that the lines of the main cracks coincide in the first approximation with the main stress areas, which does not contradict the theory [6]. New trunk cracks have the same character of appearance as the first appeared. The limit of growth of the trunk crack will be the instant when the integral deformation module of the layer reaches the value Es $\mu$, where $\mu-$ the reinforcement coefficient. New trunk cracks have the same character of education as the first educated. The limit of growth of the main crack will be the instant when the integral deformation module of the layer reaches the value Es $\cdot \mu$, where $\mu$ is the reinforcement factor. From this moment, the influence of concrete (concrete matrix) on the rigidity of the layer is excluded and therefore only the reinforcement works in the normal section passing along the trunk crack. This moment occurs almost simultaneously at once in two directions $\mathrm{X}$ and $\mathrm{Y}$. The subsequent work of the layer is connected with the achievement of stress in the reinforcement of the limiting values - the design resistance of the reinforcing steel to the stretching Rs [7] - this is the destruction of the layer. Achieved results could be applied in other fields of construction, such as hydraulic [20-24] and agricultural engineering [25-31].

\section{Summary}

The study of structural material of the high-pressure hull requires the computer simulation of the applied structural material. The laboratory experiment is both time and resourceconsuming method, which is a significant disadvantage. The authors proposed finite element modeling of structural material by adapting modern software systems for calculating the considered models. The developed method of computer modeling of HRC allows to obtain the results of calculation (numerical experiment) having values close to the values obtained from the results of the laboratory experiment, but excluding the shortcomings of laboratory research. The proposed method could be applied in other engineering fields of knowledge, including the hydraulic engineering.

\section{References}

1. A.A. Shubin, P.K. Tulin, I.V. Potseshkovskaya, International Journal of Applied Engineering Research, 12(8), 1742-1751 (2017).

2. N. Lukuttsova, International Journal of Applied Engineering Research, 10(15), 3512035124 (2015).

3. A. Darquennes, M.I.A. Khokhar, E. Rozière, A. Loukili, F. Grondin, S. Staquet, Construction and Building Materials, 25(4), 1836-1847 (2011). 
4. S.W. Kang, S.G. Hong, Fire Technology, 39(1), 9-22 (2003).

5. V.V. Budaeva, E.I. Makarova, E.A. Skiba, G.V. Sakovich, Catalysis in Industry, 5(4), 335-341 (2013).

6. A. Nefedova, J. Bykova, M. Kukolev, S. Kosov, A. Zajacs, A. Borodinecs, MATEC Web of Conferences, 2016, Article number 02010 (2016).

7. A.A. Rezanov, Scientific Herald of the Voronezh State University of Architecture and Civil Engineering. Construction and Architecture, 4, 13-27 (2012).

8. A.S. Inozemtcev, E.V. Korolev, Advances in Cement Research, 28(2), 92-98 (2016).

9. C. Feng, Electronic Journal of Geotechnical Engineering, 20(24), 12009-12016 (2015).

10. G. Östberng, H.O. Andrén, Metallurgical and Materials Transactions A: Physical Metallurgy and Materials Science, 37(5), 1495-1506 (2006).

11. A. Darquennes, S. Staquet, B. Espion, M.-P. Delplancke-Ogletree, Cement and Concrete Composites, 33(3), 368-379 (2011).

12. K. Buss, D. Mari, Materials Science and Engineering: A., 370(1-2), 163-167 (2003).

13. V.S. Bakunov, U.Sh. Shayakhmetov, Refractories and Industrial Ceramics, 48(1), 7376 (2007).

14. L.V. Ivanovna, S.Y. Petrovich, International Journal of Applied Engineering Research, 11(14), 8377-8378 (2016).

15. U.Sh. Shayakhmetov, V.S. Bakunov, V.R. Bikbulatov, I.M. Valeev, Glass and Ceramics, 63(5-6), 192-195.

16. A.V. Benin, A.S. Semenov, S.G. Semenov, Journal of Achievements in Materials and Manufacturing Engineering, 39(2), 168-175 (2010).

17. A.A. Bykov, B.P. Matveenko, G.S. Serovaev, I.N. Shardakov, A.P. Shestakov, Mechanics of Solids, 50(2), 160-170 (2015).

18. M.I. Alam, D. Kim, International Journal of Concrete Structures and Materials, 6(2), 101-110 (2012).

19. M.J. Roth, C.D. Eamon, T.R. Slawson, T.D. Tonyan, A. Dubey, ACI Materials Journal, 107(2), 185-194 (2010).

20. A. Makarov, A. Mihailova, N. Arefiev, S. Pavlov, T. Chashchina, V. Terleev, V. Badenko, Procedia Engineering, 117, 225-231 (2015).

21. R.A. Poluektov, V.V. Terleev, Russian Meteorology and Hydrology, 12, 73-77 (2005).

22. V.V. Terleev, W. Mirschel, V.L. Badenko, I.Yu. Guseva, Eurasian Soil Science, 50(4), 445-455 (2017).

23. S. Medvedev, A. Topaj, V. Badenko, V. Terleev, IFIP Advances in Information and Communication Technology, 448, 252-261 (2015).

24. V.V. Terleev, A.O. Nikonorov, I. Togo, Yu.V. Volkova, R.S. Ginevsky, V.A. Lazarev, E.R. Khamzin, V.V. Garmanov, W. Mirschel, L.I. Akimov, Magazine of Civil Engineering, 2, 84-92 (2017).

25. V.V. Terleev, W. Mirschel, U. Schindler, K.-O. Wenkel, Journal International Agrophysics, 24(4), 381-387 (2010). 
26. N. Arefiev, V. Garmanov, V. Bogdanov, Yu. Ryabov, V. Terleev, V. Badenko, Procedia Engineering, 117, 26-31 (2015).

27. V.V. Terleev, A.G. Topazh, W. Mirschel, Russian Meteorology and Hydrology, 40(4), 278-285 (2015).

28. N. Arefiev, V. Terleev, V. Badenko, Procedia Engineering, 117, 39-44 (2015).

29. V. Badenko, V. Terleev, A. Topaj, Applied Mechanics and Materials, 635-637, 16881691 (2014).

30. N. Arefiev, V. Badenko, A. Nikonorov, V. Terleev, Yu. Volkova, Procedia Engineering, 117, 20-25 (2015).

31. A. Nikonorov, S. Pavlov, V. Terleev, N. Arefiev, V. Badenko, Yu. Volkova, Procedia Engineering, 117, 258-263 (2015). 